\title{
First eddy covariance flux measurements by PTR-TOF
}

\author{
M. Müller ${ }^{1,2}$, M. Graus ${ }^{1}$, T. M. Ruuskanen ${ }^{1}$, R. Schnitzhofer ${ }^{1,2}$, I. Bamberger ${ }^{1}$, L. Kaser ${ }^{1}$, T. Titzmann ${ }^{1}$, \\ L. Hörtnagl ${ }^{3}$, G. Wohlfahrt ${ }^{3}$, T. Karl ${ }^{1,4}$, and A. Hansel ${ }^{1}$ \\ ${ }^{1}$ Institut für Ionenphysik und Angewandte Physik, Universität Innsbruck, Innsbruck, Austria \\ ${ }^{2}$ Ionicon Analytik, Innsbruck, Austria \\ ${ }^{3}$ Institut für Ökologie, Universität Innsbruck, Innsbruck, Austria \\ ${ }^{4}$ Atmospheric Chemistry Division, National Center for Atmospheric Research, Boulder, CO 80307, USA
}

Received: 21 October 2009 - Published in Atmos. Meas. Tech. Discuss.: 14 December 2009

Revised: 15 March 2010 - Accepted: 16 March 2010 - Published: 25 March 2010

\begin{abstract}
The recently developed PTR-TOF instrument was evaluated to measure methanol fluxes emitted from grass land using the eddy covariance method. The high time resolution of the PTR-TOF allowed storing full mass spectra up to $\mathrm{m} / \mathrm{z} 315$ with a frequency of $10 \mathrm{~Hz}$. Three isobaric ions were found at a nominal mass of $\mathrm{m} / \mathrm{z} 33$ due to the high mass resolving power of the PTR-TOF. Only one of the three peaks contributed to eddy covariance fluxes. The exact mass of this peak agrees well with the exact mass of protonated methanol $(\mathrm{m} / \mathrm{z}$ 33.0335). The eddy covariance methanol fluxes measured with PTR-TOF were compared to virtual disjunct eddy covariance methanol fluxes simultaneously measured with a conventional PTR-MS. The methanol fluxes from both instruments show excellent agreement.
\end{abstract}

\section{Introduction}

The eddy covariance method has proven to be a reliable method for ecosystem-level flux determination and is widely used to assess the ecosystem $\mathrm{CO}_{2}$ exchange (Baldocchi, 2003). Volatile organic compounds (VOC) play a central role in atmospheric oxidation processes and the formation of secondary organic aerosol (e.g. Monks et al., 2010; Hallquist et al., 2009). For direct eddy covariance measurements fast sensors with a high temporal resolution $(5-20 \mathrm{~Hz})$ are necessary to measure the concentration fluctuations caused by turbulent transport (Dabberdt et al., 1993). Up to now, only a few instruments for fast VOC detection with data acquisition rates of typically $10 \mathrm{~Hz}$ are available. Each instrument is limited

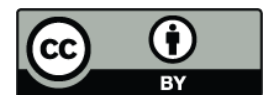

Correspondence to: A. Hansel (armin.hansel@uibk.ac.at) to the detection of a few compounds, e.g. acetone and formic acid (Shaw et al., 1998), peroxy acetyl nitrates (Turnipseed et al., 2006) and isoprene (Guenther and Hills, 1998).

For the last decade, Proton Transfer Reaction Mass Spectrometers (PTR-MS) have proven to be valuable tools for atmospheric research. The PTR-MS was developed in the mid nineties as a fast, real-time organic trace gas analyzer (Hansel et al., 1995; Lindinger et al., 1998). Since then, PTR-MS found its place in various scientific fields such as food chemistry, medicine and atmospheric research, and wherever a fast detector for VOCs is required. The applications of PTRMS in atmospheric research were recently reviewed by De Gouw and Warneke (2007). The performance of PTR-MS instruments significantly improved over the last years. Today, limits of detection are at the low pptv range, typically $10 \mathrm{pptv}$ ( signal/noise $=2$, integration time $1 \mathrm{~s} \mathrm{per} \mathrm{m} / \mathrm{z}$ ). Nevertheless quadrupol mass spectrometers (Q-MS), as used in conventional PTR-MS instruments, show several analytical limitations. Q-MS usually have unity mass resolving power and ions of different $\mathrm{m} / \mathrm{z}$ are measured sequentially. These constraints result in a restricted set of compounds $(\mathrm{m} / \mathrm{z})$ for fast measurements and a limited selectivity of the PTR-MS. Karl et al. (2001a, b) demonstrated the feasibility of eddy covariance measurements of VOC fluxes from crop and hay harvesting. For those experiments their PTR-MS instrument had been redesigned to achieve a response time of $\sim 65 \mathrm{~ms}$, the integration time per mass channel was set to $100 \mathrm{~ms}$ to collect $10 \mathrm{~Hz}$ VOC time series and the number of mass channels was mostly restricted to two masses at a time, e.g. $m / z 33$ and $m / z, 5$ for methanol and acetaldehyde, respectively.

In order to measure VOC fluxes of a wider suite of compounds using PTR-MS, different methods have been derived from eddy covariance. Based on intermittent sampling strategies (Lenschow et al., 1991) the concepts of disjunct eddy

Published by Copernicus Publications on behalf of the European Geosciences Union. 
covariance (DEC; Rinne et al., 2001) and, more recently, virtual disjunct eddy covariance (Karl et al., 2002) were introduced. These methods allow flux quantification with repetition rates of a set of compounds of a few seconds at acquisition times for a single compound between $0.2 \mathrm{~s}$ and $1 \mathrm{~s}$. Relaxed eddy accumulation (REA) (Businger and Oncley, 1990) is another more indirect micrometeorological method that has been used in conjunction with PTR-MS. REA relies on capturing air samples in up and down-drafts, storing these in separate gas reservoirs. Graus et al. (2006), have shown a REA method for measuring canopy-fluxes of isoprenoid compounds using PTR-MS above a pine forest. Despite this progress, several challenges remain when measuring VOC fluxes with PTR-MS. For example, when using a Q-MS the superposition of isobaric ionic compounds could mask the net flux, if one compound is deposited and another one is emitted.

In the last decade several mass spectrometric approaches have been explored to increase the selectivity of PTR-MS. In addition to coupling a gas chromatographic column to a PTR-MS (GC-PTR-MS, Karl et al., 2001c, Warneke et al., 2003), mass spectrometric techniques using multiple MS $\left(\mathrm{MS}^{n}\right)$ capable detectors (i.e. Prazeller et al., 2003; Warneke et al., 2005a; Mielke et al., 2008; Müller et al., 2009) have been developed. Isomers are identified according to specific fragmentation patterns obtained by collision induced dissociation (CID). However, these techniques showed only limited identification capabilities when used in atmospheric research, e.g. the separation capability at ambient levels of the isoprene photo-oxidation products methacrolein and methyl vinyl ketone (Mielke et al., 2008), as well as the on-line separation of acetone and propanal (Warneke et. al., 2005b) could be demonstrated.

PTR ion sources have also been interfaced with various time-of-flight mass spectrometers (TOF-MS). The first instrument, the PTR-TOF-MS (Blake et al., 2004) showed a mass resolving power $(\Delta m / m)$ of about 1000 . Although this mass resolving power is higher than that of a commercial PTR-MS (Ionicon Analytik, Austria), it is not sufficient to separate isobaric ions. These early TOF-MS developments for VOC analysis based on proton-transfer-reactions were challenged by poor sensitivities compared to conventional PTR-MS. A new generation of high mass resolution TOFMS (G-TOF, TOFWERK AG, Switzerland) has largely overcome the sensitivity issue (Jordan et al., 2008) making PTRTOF (Ionicon Analytik, Austria) tractable for atmospheric trace gas measurements in the pptv range. Currently a mass resolving power of about 5000 and a mass accuracy of about 5 ppm can be achieved (Graus et al., 2010). This is sufficient to separate most atmospherically relevant protonated isobaric VOCs and to identify the corresponding empirical formulas. Even if sensitivities are about one order of magnitude lower compared to a conventional PTR-MS (Ionicon Analytik, Austria) when measuring one single mass channel, the high duty cycle of the TOF-MS (all ions are measured simultaneously) makes it a valuable tool for fast and selective analysis of complex mixtures of VOCs. Most importantly, the TOF-MS allows the acquisition of full mass spectra at time resolutions of $10 \mathrm{~Hz}$, a necessary prerequisite for direct eddy covariance measurements. The simultaneity of the data acquisition allows long time data integration of the high time resolved data without any loss of signal.

For the first time we demonstrate the ability of the PTRTOF for flux measurements above a temperate grassland and show an example of direct eddy flux determination for ions at $\mathrm{m} / \mathrm{z}$ 33. We compare eddy covariance fluxes obtained from a PTR-TOF with virtual disjunct eddy covariance fluxes measured with a conventional PTR-MS. We discuss our solutions for the complex data processing necessitated by a data volume of about $10 \mathrm{~GB}$ per day of highly resolved, compressed raw PTR-TOF data.

\section{Experimental setup}

\subsection{Field site and instrumentation}

A PTR-TOF and a PTR-MS instrument were deployed at a well-characterized field site for VOC flux measurements above temperate mountain grassland. The field site is located in the Stubai valley, Austria, close to the village of Neustift $\left(47^{\circ} 07^{\prime} \mathrm{N}, 11^{\circ} 19^{\prime} \mathrm{E}\right)$ at $970 \mathrm{~m}$ a.s.l. in the middle of the flat valley bottom. The average annual rainfall at the site is $852 \mathrm{~mm}$ and the average annual temperature is $6.5^{\circ} \mathrm{C}$. A detailed description of the field site, including a description of vegetation, soil and climate, is given by Hammerle et al. (2008) and Wohlfahrt et al. (2008).

The three wind components and speed of sound were measured using a 3-D sonic anemometer (R3IA, Gill Instruments, USA) at $20 \mathrm{~Hz}$ time resolution. A High Sensitivity PTR-MS was installed for VOC quantification and flux detection using the virtual disjunct eddy covariance method (Karl et al., 2002). The VOC inlet was mounted $2.5 \mathrm{~m}$ above ground, about $20 \mathrm{~cm}$ below the centre of the 3 $\mathrm{D}$ sonic anemometer. The PTR-MS was connected to the VOC inlet by a $12 \mathrm{~m}$, temperature - stabilized $\left(T_{\text {inlet }}=35^{\circ} \mathrm{C}\right)$ $1 / 4^{\prime \prime}$ Teflon ${ }^{\circledR}$ line (ID=0.39 mm) pumped with $91 /$ min ambient air. The instrument was operated at 2.3 mbar drift tube pressure and $550 \mathrm{~V}$ drift tube voltage. The total response time of the whole system was about $1.6 \mathrm{~s}$ for methanol. For flux determination a set of $12 \mathrm{~m} / \mathrm{z}$ ratios was sequentially measured at a repetition rate of about $2 \mathrm{~s}$; integration times for each $m / z$ were $0.2 \mathrm{~s}$ or less. The instrument was calibrated weekly. Zero measurements were performed every $25 \mathrm{~min}$ lasting for $5 \mathrm{~min}$. All acquisition times were synchronized using a NTP time server. A detailed description of the PTRMS measurements is discussed by Bamberger et al. (2010). 


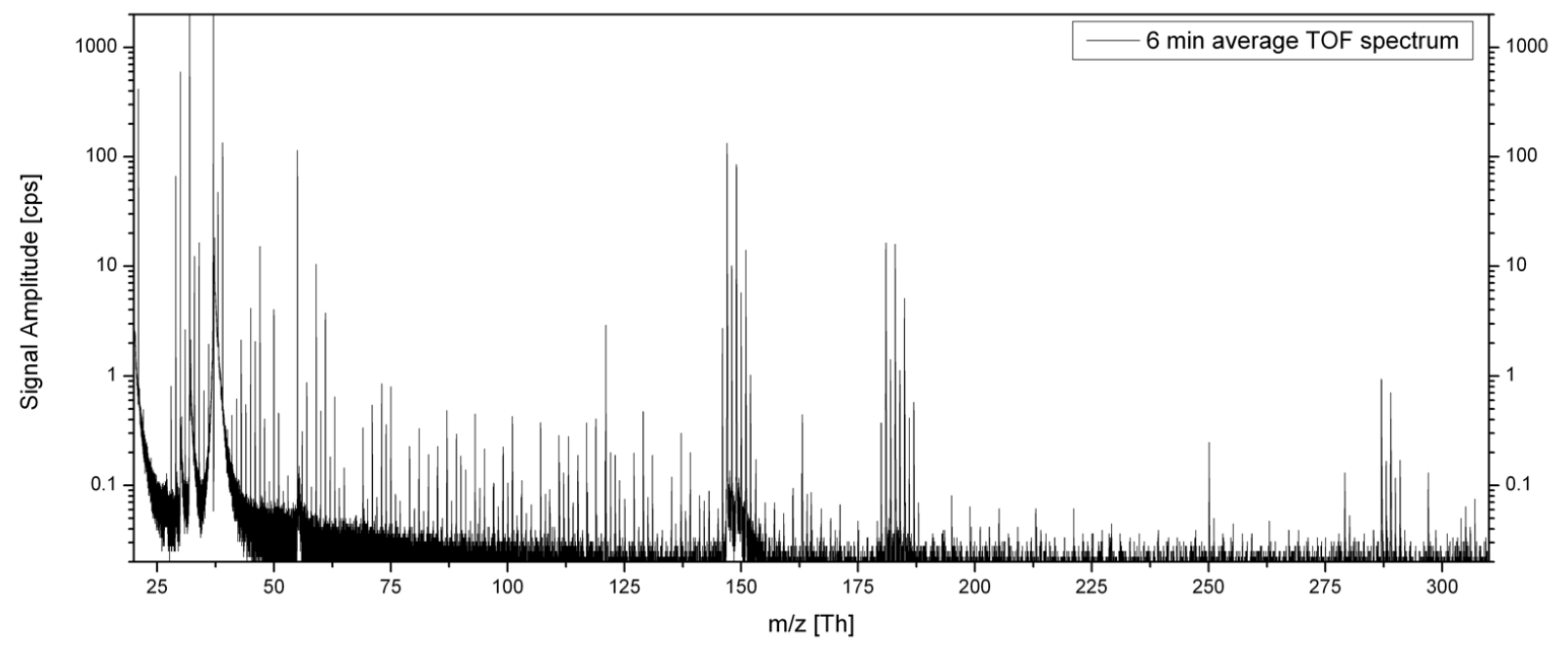

Fig. 1. Six minutes sum spectrum from $\mathrm{m} / \mathrm{z}, 20$ to $\mathrm{m} / \mathrm{z} 315$ containing 150000 data acquisition bins ( $0.2 \mathrm{~ns}$ time intervals).

\subsection{PTR-TOF}

The PTR-TOF sampled from the same VOC inlet line as the PTR-MS. The PTR-TOF drift tube was operated at $600 \mathrm{~V}$ drift voltage and $2.3 \mathrm{mbar}$ drift tube pressure and heated to $50^{\circ} \mathrm{C}$. This corresponds to an $E / N$ ratio of about $130 \mathrm{Td}(E$ being the electric field strength and $N$ the gas number density; $1 \mathrm{Td}=10^{-17} \mathrm{~V} \mathrm{~cm}^{2}$ ). A detailed description and characterization of the PTR-TOF instrument can be found in Graus et al. (2010).

For TOF-MS data acquisition, ions were pulsed into the field free region every $30 \mu$ s. With a Multi Channel Plate and a Time to Digital Converter (TDC) the arrival times of all pulsed ions were detected with $0.2 \mathrm{~ns}$ time resolution resulting in 150000 "bins" per spectrum. The spectral information of 3333 pulse cycles were co-added to produce $10 \mathrm{~Hz}$ time series of full PTR-TOF spectra and the data was stored in hdf5 file format (http://www.hdfgroup.org/) using the data acquisition software TOF-DAQ v1.72 (Tofwerk AG, Switzerland). To keep the files easily manageable, 3600 spectra were stored in a single hdf5 file resulting in $6 \mathrm{~min}$ $10 \mathrm{~Hz}$-data segments including the 6 min sum spectra. Figure 1 depicts such a 6 min sum spectrum from $\mathrm{m} / \mathrm{z} 20$ to $m / z 315$.

Background measurements (zero calibration) were automatically performed every $7 \mathrm{~h}$ each lasting $25 \mathrm{~min}$ using VOC-free air at ambient humidity levels. This air was provided by a continuously flushed, home-built catalytic converter at $350^{\circ} \mathrm{C}$. Sensitivity calibrations were performed twice a week by dynamic dilution of VOCs from a multicomponent gas cylinder (Apel Riemer Environmental Inc.) into purified air. On 26 July 2009, a methanol sensitivity of $33 \mathrm{cps} / \mathrm{ppbv}$ and an acetone sensitivity of $69 \mathrm{cps} / \mathrm{ppbv}$ were achieved.
To provide peaks of exactly known $\mathrm{m} / \mathrm{z}$ for the timeof-flight to $\mathrm{m} / \mathrm{z}$ conversion (described in Sect. 4.1), traces of dichlorobenzene $(m / z=146.9763)$ and trichlorobenzene $(m / z=180.9373)$ were continuously added into the VOC inlet by diffusion through a capillary.

The mass resolving power $(R=m / \Delta m)$ and the mass accuracy were determined using the calibration data providing a suite of mass peaks distributed throughout the instrument's mass range. $R$ was calculated from the full width at half maximum of individual mass peaks and the mass accuracy was determined by the maximum relative mass deviation of the measured calibration compound masses from their respective theoretical exact masses. During these field experiments the PTR-TOF achieved a mass resolving power of 4800 and a mass accuracy better than $10 \mathrm{ppm}$. This is sufficient to distinguish empirical ionic formulas for most atmospheric compounds.

\subsection{VOC flux analysis}

VOC fluxes were calculated applying the eddy covariance method to the $10 \mathrm{~Hz}$ PTR-TOF signal and the $20 \mathrm{~Hz}$ sonic anemometer data. The routine includes a three-axis coordinate rotation of the wind data based on McMillan (1988), a re-sampling of the $20 \mathrm{~Hz}$ wind data to match the $10 \mathrm{~Hz} \mathrm{VOC}$ data, a maximum covariance analysis of the VOC concentrations and the vertical wind velocity for time lag analysis, and calculation of the covariance $F$ between the vertical wind speed and the VOC concentrations (block averaging, no detrending). By using this routine, half hourly mean flux values were calculated.

For the PTR-MS data, half-hourly mean VOC fluxes (virtual DEC) were calculated based on the same postprocessing steps as above, except for that only a subset of the wind data was used. A detailed discussion of the PTR-MS flux analysis will be given by Bamberger et al. (2010). 


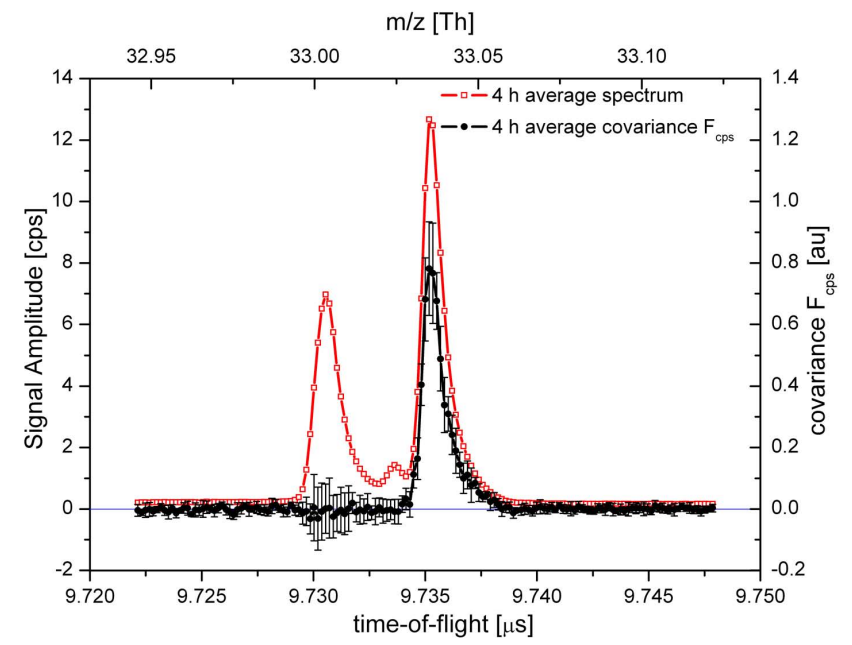

Fig. 2. Cutout of a 4 h (26 July 2009; 10:00-14:00) integrated PTR-TOF mass spectral signal at $\mathrm{m} / \mathrm{z}, 33$ (red squares) and the corresponding bin-wise calculated covariances $F_{\mathrm{cps}}^{\text {bin }}$ (black dots) with corresponding standard deviation intervals (calculated based on $30 \mathrm{~min}$ resolved data) in arbitrary units (au).

\section{Bin-wise flux calculation}

The most challenging analysis step to get flux data would be the eddy covariance computation of the wind data with the 150000 individual PTR-TOF time bins. Figure 2 depicts a cutout of a $4 \mathrm{~h}$ (26 July 2009; 10:00-14:00) integrated PTR-TOF spectrum at $m / z$ 33. Three mass peaks are clearly separated, one at $m / z=32.9957$ (a superposition of $\mathrm{O}^{18} \mathrm{O}^{+}$ and $\left.\mathrm{O}_{2} \mathrm{H}^{+}\right)$, another one at $m / z=33.0204\left(\mathrm{DNOH}^{+}\right.$, chemical instrumental background) and at $m / z=33.0335\left(\mathrm{CH}_{5} \mathrm{O}^{+}\right)$. Covariances, $F_{\mathrm{cps}}^{\mathrm{bin}}$, of vertical wind speed and signal intensities (in cps) of 150 individual TOF bins (black dots in Fig. 2) were calculated for 8 consecutive $30 \mathrm{~min}$ periods (26 July 2009; 10:00-14:00). To prevent effects caused by possible different instrumental time responses of the three mass peaks, time lags have been calculated individually for every single TOF bin using the maximum covariance method.

Figure 2 demonstrates, that a significant covariance contribution, i.e. flux, was only observed for the methanol $(\mathrm{m} / \mathrm{z}=33.0335)$ peak, from about $\mathrm{m} / z=33.03$ to $\mathrm{m} / z=33.06$. For the other two mass peaks, from $m / z=32.98$ to $m / z=33.015$ and from $\mathrm{m} / \mathrm{z}=33.015$ to $\mathrm{m} / \mathrm{z}=33.03$, no pronounced covariance peak but an increased noise level is visible. Using conventional PTR-MS the correlated noise of these background ions adds to an increased total noise level. Note, that flux contributions, e.g. emission of one and deposition of another compound measured on a nominal mass, will additionally affect the PTR-MS flux results.

In order to design a computationally optimized algorithm, the complexity of calculating covariances for the individual 150000 bins needs to be reduced. This can be achieved by defining bin intervals that potentially carry a significant flux contribution. Integration of the ionic signals over these bin intervals results in increased signal intensities and consequently reduces the flux detection limit. This data reduction step generates socalled $10 \mathrm{~Hz}$ stick spectra. In the following section, a detailed description of this data processing and data reduction is given.

\section{Data processing and data reduction}

A precise and fully automated data processing is important to handle the enormous data amount caused by long-term acquisition of highly time resolved TOF mass spectra. Different approaches to the arising problems have been reported in the literature, e.g. the solutions applied by high-resolution time-of-flight aerosol mass spectrometry (HR-TOF-AMS, DeCarlo et al., 2006) that utilizes a similar TOF-MS instrument. Nevertheless, different data acquisition systems as well as the high mass peak capacity of the PTR-TOF's soft ionization method demand a different data reduction approach. In principle, the data reduction faces three challenges:

1. Temperature changes lead to slow variations in the length of the of the ion's flight path. This has to be corrected to gain high mass accuracies (Sect. 4.1).

2. Several mass peaks may be present at one nominal mass (multiple peaks, Sect. 4.2).

3. At high time resolutions (e.g. $10 \mathrm{~Hz}$ ) signal intensities of most mass peaks are very low (Sect. 4.3).

Based on MATLAB 7.6.0 (R2008a, The MathWorks, Inc, USA) we developed a custom analysis routine that retains sufficient mass spectral information after filtering the raw data (150000 bins per single spectrum) piecewise. To reduce the analysis time, the routine utilizes $6 \mathrm{~min}$ sum spectra to perform necessary mass spectrometric corrections. To solve the challenges described above, the data processing routine consists of three sub routines: the time-of-flight to $\mathrm{m} / \mathrm{z}$ conversion routine calculates a statistically most accurate mass scale (Sect. 4.1), the peak detection routine generates a peak list of all detected mass peaks (Sect. 4.2), and the signal analysis routine utilizes the peak list for mass peak fitting, mass peak analysis and $10 \mathrm{~Hz}$ stick spectra calculation (Sect. 4.3). These $10 \mathrm{~Hz}$ stick spectra were subsequently used for eddy covariance flux calculations.

The three sub routines are based on the following peak fitting algorithm:

The first important step is the determination of a function to approximate a PTR-TOF mass peak. The peak shape generated by the instrument is asymmetric and can be described by a superposition of four dependent Gaussian peaks. 

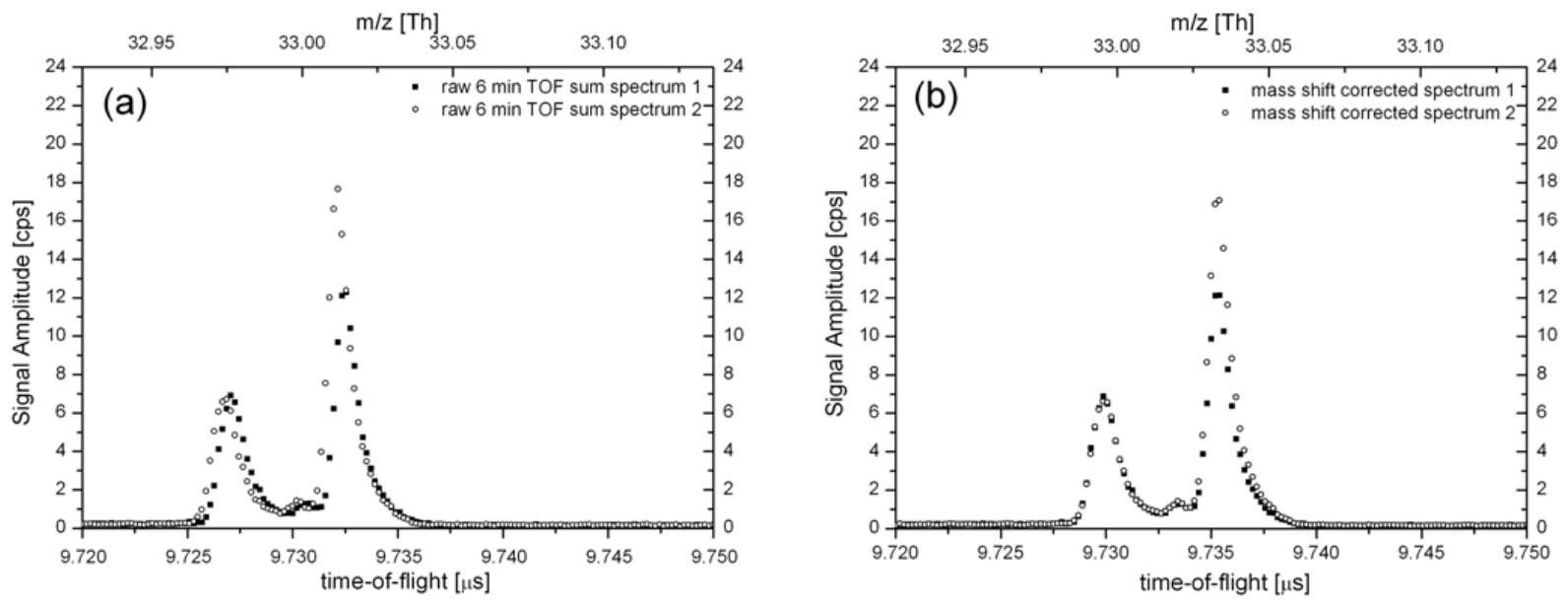

Fig. 3. (a) two raw PTR-TOF sum spectra (26 July 2009, at 10:00 (black squares) and 23:00 (circles)) at $\mathrm{m} / \mathrm{z}$ 33, (b) same sum spectra after performing a mass shift correction.

$$
\begin{aligned}
S I(t) & =y_{0}+A \cdot\left[a \cdot G_{1}(\Delta)\left(t-t_{0}\right)\right. \\
& +b G_{2}(\Delta)\left(t-t_{0}-0.8 \cdot \Delta\right) \\
& +c \cdot G_{3}(\Delta / \sqrt{ } 3.5)\left(t-t_{0}+\Delta\right) \\
& \left.+d \cdot G_{4}(\Delta / \sqrt{ } 6)\left(t-t_{0}-e \cdot \Delta\right)\right]
\end{aligned}
$$

The coefficients, $a, b, c, d$, and $e$, which govern the relative positions and proportions of the four contributions $\left(G_{1,2,3,4}\right)$ are determined by applying that function to identified, single well established isobaric peaks in the full TOF spectrum. In the following these peaks are termed mass scale correction peaks (see Sect. 4.1). The position and proportion coefficients are optimized for each 6 min sum spectrum and kept constant for all peak fitting in the respective time period. The remaining independent coefficients in the final peak shape function are the peak area $A$, the peak width $\Delta$ (full width at half maximum; FWHM), the peak center $t_{0}$ and the peak offset $y_{0}$. The dependent variable is the time of flight $t$. The function in Eq. (1) was used to fit all mass peaks by applying the nonlinear least squares fitting method.

For every nominal mass $(m / z-0.3>m / z>m / z+0.3)$, a superposition of the peak shape $S I\left(t_{1}, t_{2}, \ldots, t_{n}\right)=S I\left(t_{1}\right)+S I\left(t_{2}\right)+\ldots+S I\left(t_{n}\right)$ with a constant offset $y_{0}$ is fitted. The number of the superposed peaks $n$ is assigned by the number of detected peaks according to a peak list (see Sect. 4.2). To increase the fit quality, tight fitting boundaries for the peak width $\Delta$ and the peak center $t_{n}$ are used. According to Coles et al. (1995) the expected coherence of the time of flight $t$ and the width $\Delta$ is:

$\Delta=a_{1}\left(t^{2} / b_{1}^{2}+1\right)^{1 / 2}$

Coefficients $a_{1}$ and $b_{1}$ are calculated by fitting Eq. (2) to the time of flights $t_{0}$ and the widths $\Delta$ of the mass scale correction peaks. For every sum spectrum, peak width estimates for all mass peaks are calculated and used as start parameters. To reduce the degree of freedom for multiple peaks, $\Delta$ is set equal for every peak on each nominal mass; $\Delta$ is constrained to $\pm 8 \%$ of the peak width estimate. The start parameter for the peak center $t_{n}$ is then given as the position according to the peak list. The constraints for the peak centers are set as $\Delta / 2$ around the expected center $t_{n}$.

\subsection{Time-of-Flight to $m / z$ conversion}

Temperature variations of the TOF-MS can cause a slow change in the length of the ion's flight path over time, slightly changing the ion's time-of-flight. Therefore frequent $\mathrm{m} / \mathrm{z}$ corrections are necessary to achieve a high mass accuracy. Figure 3a depicts two uncorrected (raw) 6 min sum spectra at $\mathrm{m} / \mathrm{z} 33$, both recorded on 26 July 2009, at 10:00 and 23:00, respectively. By looking at the peak centers, a distinct shift in time-of-flight is visible that would affect the measured exact mass assignment. For compound identification, an accurate, precise and fully automated conversion of the time-of-flight to a mass scale is necessary.

Therefore, the peak fitting algorithm is applied on the mass scale correction peaks, in this case the primary ion isotopes $\mathrm{H}_{3} \mathrm{O}^{18+}(\mathrm{m} / \mathrm{z}=21.0221)$ and $\mathrm{H}_{5} \mathrm{O}^{16} \mathrm{O}^{18+}(\mathrm{m} / \mathrm{z}=39.0327)$, as well as the continuously added mass calibration compounds dichlorobenzene $(m / z=146.9763)$ and trichlorobenzene $(\mathrm{m} / \mathrm{z}=180.9373)$.

The relation of the time of flight $t$ and the mass scale $m$ is calculated according to the simple Eq. (3) (e.g. Brown and Gilfrich, 1991) by fitting the coefficients $\alpha$ and $\beta$.

$m=((t-\beta) / \alpha)^{2}$

A temperature stabilized housing of the PTR-TOF minimizes time-of-flight shifts, caused by small temperature changes of the TOF-MS. On time scales of about $10 \mathrm{~min}$ no significant 
shift was observed (data not shown). Therefore, the timeof-flight to $m / z$ conversion coefficients were calculated based on individual 6 min sum spectra for the respective period. To allow the superposition and long time integration of all analyzed spectra, an interpolation of the time bins of each mass spectrum was performed to get congruent 6 min sum spectra.

After these correction steps a high mass accuracy and precision could be achieved for the hole measurement campaign. Maximum relative mass deviations of less than $10 \mathrm{ppm}$ were determined for mass peaks higher than $m / z=40$ based on weekly instrumental calibrations. Figure $2 \mathrm{~b}$ depicts two congruent sum spectra after performing the mass scale conversion and correction algorithms.

\subsection{Peak detection}

The purpose of the peak detection routine is the compilation of a complete set of detectable mass signals (peak list). This task is split into two analysis steps, first, a search for distinct peaks in the spectrum and, second, a fit residual-analysis to uncover hidden or less pronounced peaks (e.g. peaks covered in a shoulder of a larger peak).

1. Every 6 min sum spectrum is scanned for peaks by using the MATLAB peak search function "peakdet" (http:// www.billauer.co.il/peakdet.html) and the peak maxima are added to a preliminary peak list. A dynamic, noise dependent threshold for peak maxima detection is used. For this first peak identification step mass peak maxima must be separated by at least $130 \mathrm{ppm}$ to be recognized as a new mass peak.

2. The fit residual-analysis is performed on a whole day average spectrum. Therefore the peak fitting algorithm is applied according to the preliminary peak list. For every nominal mass, the smoothed fit residual is analyzed for further potentially significant peak maxima. Is a maxima of the residual detected, the fitted peak center of the highest residual peak is added to the peak list. This step is repeated until one of the following criteria is fulfilled:

- A maximum of 5 mass peaks per nominal mass is listed

- The $R^{2}$ for the fit is greater than 0.995

- The residual peaks are not significantly higher than the expected noise (the noise threshold is calculated by the intensity deviations outside the corresponding nominal mass intervals)

In this way a peak list containing about 470 mass peaks was generated for the total mass spectrum shown in Fig. 1 and three peaks at $m / z 33$ shown in Fig. $2, m / z=32.9957$ $\left(\mathrm{O}^{17} \mathrm{O}^{+}\right.$and $\left.\mathrm{O}_{2} \mathrm{H}^{+}\right), m / z=33.0204\left(\mathrm{DNOH}^{+}\right.$, instrumental background) and $m / z=33.0335\left(\mathrm{CH}_{5} \mathrm{O}^{+}\right.$, methanol), respectively.

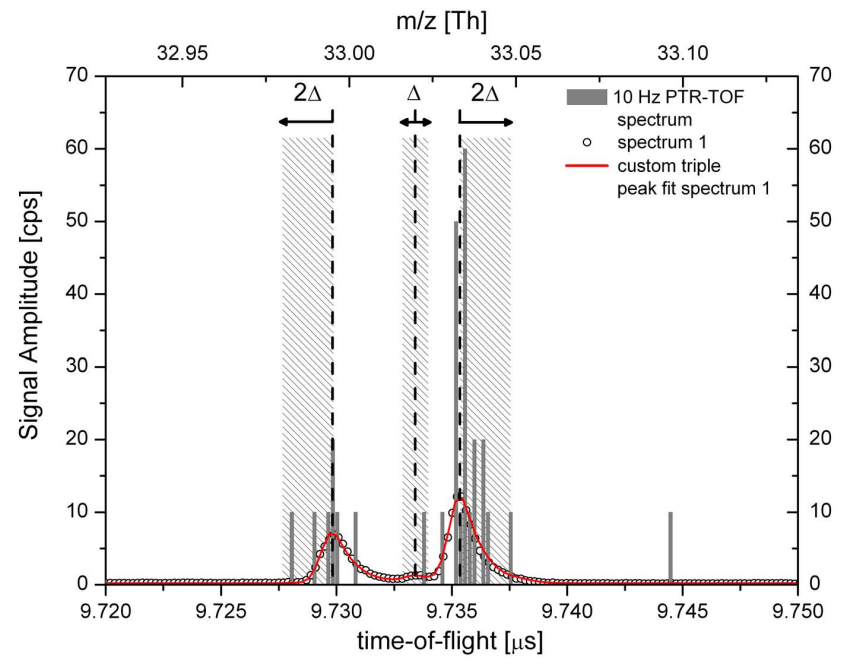

Fig. 4. Peak fitted 6 min sum spectrum 1 (26 July 2009, at 10:00) together with a single $10 \mathrm{~Hz}$ spectrum within that $6 \mathrm{~min}$ and corresponding summation intervals (hatched areas).

\subsection{Signal analysis}

For signal analysis, the above described peak fitting algorithm was applied on the 6 min sum spectra, utilizing the updated peak list. Figure 4 depicts a $6 \mathrm{~min}$ sum spectrum at $\mathrm{m} / \mathrm{z}, 33$ that was fitted by a triple superposition of the peak function $S I\left(t_{1}, t_{2}, t_{3}\right)=S I\left(t_{1}\right)+S I\left(t_{2}\right)+S I\left(t_{3}\right)$. For peak quantification the resulting data were corrected according to the duty cycle and the signals were normalized to the primary ion signal (cps $\rightarrow$ ncps; see e.g. Herbig et al., 2009). Up to this point in the signal analysis all data processing is based on the 6 min sum spectra.

Figure 4 demonstrates that all three peaks at nominal mass $\mathrm{m} / \mathrm{z} 33$ can be fitted successfully in the $6 \mathrm{~min}$ sum spectrum, but applying the peak fitting algorithm directly to every $10 \mathrm{~Hz}$ spectrum might fail in most cases. To overcome this drawback, mass scale intervals were predefined for each peak list entry and all counts within these intervals were summed separately for each $10 \mathrm{~Hz}$ spectrum. For the superposition of a number of peaks per nominal mass (multiple peaks) it is important to minimize the statistical influence of neighboring peaks by adapting the interval position and length. For single peaks we chose an interval of 4 times the peak width $\Delta$ around the peak center. For all multiple peaks, the interval margins of the outer two peaks were set to the peak center and $2 \Delta$ away from the other peaks, respectively; for all inner peaks a single $\Delta$-interval around the centers was chosen. For barely separated multiple peaks, the selected intervals might overlap. In such cases, the sum of the influencing mass peaks must be taken to prevent misinterpretations. Figure 4 depicts a segment at $m / z, 33$ of a single $10 \mathrm{~Hz}$ spectrum, a $6 \mathrm{~min}$ sum spectrum with its best fit and the corresponding predefined summation intervals. For obvious reasons the summed 


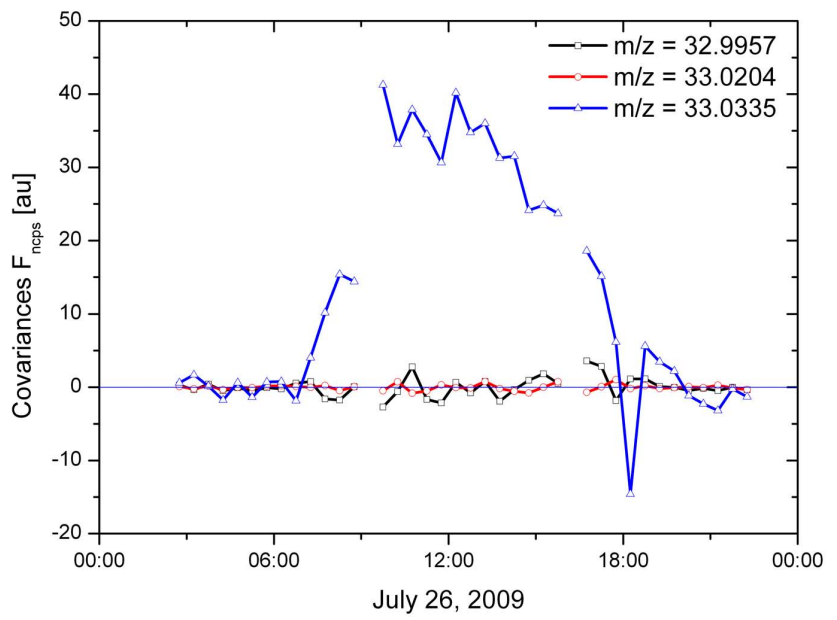

Fig. 5. Calculated covariances $F_{\text {ncps }}^{\text {stick }}$ for $m / z=32.9957 \mathrm{Th}$, $m / z=33.0204 \mathrm{Th}$ and $m / z=33.0335 \mathrm{Th}$ (methanol) in arbitrary units (au).

up signal intensities within those intervals (hatched areas in Fig. 4) only reflect portions of the respective total ion signal of each of the mass peaks. The individual $10 \mathrm{~Hz}$ stick intensities are up-scaled according to the ratio of 6 min integrated $10 \mathrm{~Hz}$ stick intensities to the corresponding fit areas in the 6 min sum spectrum.

\section{Demonstration of flux measurements}

\subsection{PTR-TOF flux detection}

Covariances $F_{\text {ncps }}^{\text {stick }}$ of the vertical wind speed and the peak signal intensities (in ncps) were calculated for an averaging period of $30 \mathrm{~min}$ for the mass peaks at $m / z=32.9957$ $\left(\mathrm{O}^{18} \mathrm{O}^{+}+\mathrm{O}_{2} \mathrm{H}^{+}\right), m / z=33.0204\left(\mathrm{DNOH}^{+}\right)$and $m / z=33.0335$ $\left(\mathrm{CH}_{5} \mathrm{O}^{+}\right)$, respectively (Fig. 5).

The methanol $(m / z=33.0335)$ covariance shows a clear diurnal pattern - close to zero flux during nighttime and an emission following the diurnal course of insulation and temperature during daytime. For the two other isobaric compounds, $m / z=32.9957$ and $m / z=33.0204$, both instrumental background peaks, no significant covariance was found. This result, calculated using the $10 \mathrm{~Hz}$ stick data, agrees with the bin-wise calculations depicted in Fig. 2, which shows that there is no significant covariance for $m / z=32.9957$ and $m / z=33.0204$. To compare both methods, the bin-wise calculated covariance was summed between $m / z=33.03$ and $m / z=33.06$ to get the total covariance contribution for the methanol peak. An excellent agreement was found between the bin-wise and the interval method. A linear regression between $F_{\text {ncps }}^{\text {stick }}$ and $F_{\text {ncps }}^{\text {bin }}$ for 26 July 2009, resulted in a $y$ intercept of 0.005 and a slope of $1.00 \pm 0.04$ (data not shown).

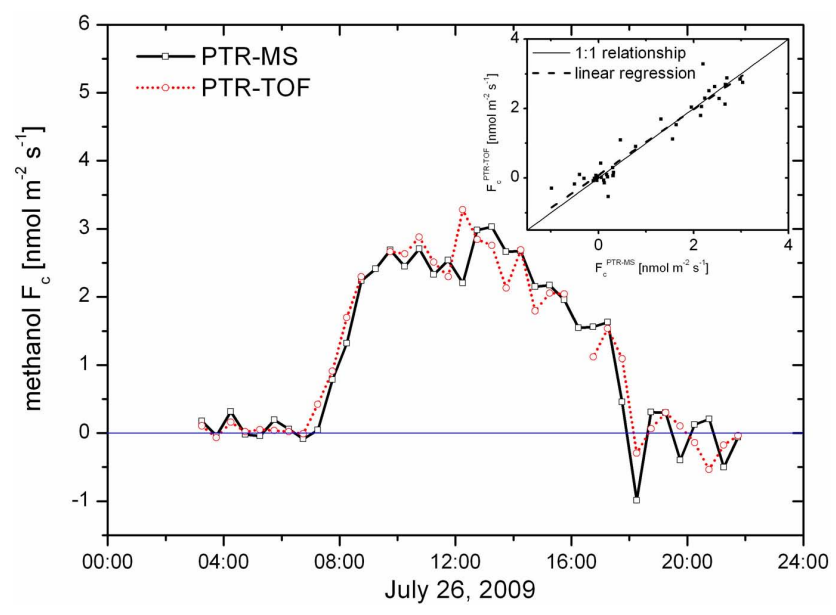

Fig. 6. Comparison of eddy covariance fluxes $F_{c}^{\mathrm{PTR}-\mathrm{TOF}}$ (red circles) and virtual disjunct eddy covariance fluxes $F_{c}^{\mathrm{PTR}-\mathrm{MS}}$ (black squares) using $10 \mathrm{~Hz}$ PTR-TOF and disjunct PTR-MS data; the inset depicts the corresponding 1:1 relationship and an orthogonal distance linear regression.

\subsection{Comparison of PTR-TOF and PTR-MS results}

Figure 6 compares the PTR-TOF methanol fluxes $F_{c}^{\text {PTR-TOF, }}$ calculated by direct eddy covariance, with the PTR-MS fluxes $F_{c}^{\mathrm{PTR}-\mathrm{MS}}$, calculated with the virtual disjunct eddy covariance method (Karl et al., 2002).

Starting from 09:00 and 16:00 two instrumental zero measurements were performed for the PTR-TOF each lasting $25 \mathrm{~min}$. Therefore no $F_{c}^{\mathrm{PTR}-\mathrm{TOF}}$ data is available for those periods. For $F_{c}^{\mathrm{PTR}-\mathrm{TOF}}$ and $F_{c}^{\mathrm{PTR}-\mathrm{MS}}$ a similar diurnal trend is visible and measured flux magnitudes compare reasonably well. A least orthogonal distance linear regression between $F_{c}^{\mathrm{PTR}-\mathrm{TOF}}$ and $F_{c}^{\mathrm{PTR}-\mathrm{MS}}$ shows a slope of 0.98 and a $y$ intercept of $0.06 \mathrm{nmol} \mathrm{m}^{-2} \mathrm{~s}^{-1}$. Both values are not significantly different from 1 and 0 , respectively. A coefficient of determination of $R^{2}=0.92$ is achieved.

\section{Conclusions}

We demonstrated that the recently developed PTR-TOF instrument is capable of measuring methanol fluxes using the direct eddy covariance method. PTR-TOF data were stored at time resolutions of $10 \mathrm{~Hz}$. Three isobaric ions at $m / z 33$ were analyzed for flux contributions. Direct analysis of high mass resolved (bin-wise) eddy covariance demonstrated that only one ion species contributed significantly to the flux magnitude of the triple peak at $m / z 33$. The signals of the other two species contributed to an increased flux noise level. This example highlights the high separation capabilities of the PTR-TOF even at $10 \mathrm{~Hz}$ time resolution.

To reduce the time consuming analysis of bin-wise flux calculations and improve flux detection limits, a new data reduction method based on stick spectra has been developed. 
The method was able to detect about 470 mass peaks above grassland. We evaluated the feasibility of eddy covariance flux measurements using PTR-TOF using three mass peaks at $\mathrm{m} / \mathrm{z}$ 33. The comparison of the two different flux calculation methods (bin and stick spectral method) showed excellent agreement. PTR-TOF methanol fluxes were also compared with vDEC fluxes determined by a conventional PTR-MS. Both methods showed excellent agreement.

Future eddy covariance measurements using PTR-TOF may help to elucidate complex exchange patterns of a multiplicity of VOCs between the biosphere and atmosphere.

Acknowledgements. This study was financially supported by the Austrian National Science Fund (P19849), and the Tyrolean Science Fund (Uni-404/486). Family Hofer (Neustift, Austria) is thanked for granting us access to the study site. Additional support was obtained by the Translational-Research-Programm (L518) of the Austrian National Science Fund and the Industry-Academia Partnerships and Pathways (IAPP; 218065) funded by the European Commission. The National Center for Atmospheric Research is operated by the University Corporation for Atmospheric Research under sponsorship from the National Science Foundation.

Edited by: R. Cohen

\section{References}

Baldocchi, D. D.: Assessing the eddy covariance technique for evaluating carbon dioxide exchange rates of ecosystems: past, present and future, Glob. Change Biol., 9, 479-492, 2003.

Bamberger, I., Hörtnagl, L., Schnitzhofer, R., Graus, M., Ruuskanen, T. M., Müller, M., Dunkl, J., Wohlfahrt, G., and Hansel, A.: Long term BVOC fluxes above mountain grassland, Biogeosciences Discuss., 7, 83-110, 2010, http://www.biogeosciences-discuss.net/7/83/2010/.

Blake, R. S., Whyte, C., Hughes, C. O., Ellis, A. M., and Monks, P. S.: Demonstration of Proton-Transfer Reaction Time-of-Flight Mass Spectrometry for Real-Time Analysis of Trace Volatile Organic Compounds, Anal. Chem., 76, 3841-3845, 2004.

Brown, R. S. and Gilfrich, N. L.: Design and performance of a matrix-assisted laser desorption time-of-flight mass spectrometer utilizing a pulsed nitrogen laser, Anal. Chim. Acta, 248, 541552, 1991.

Businger, J. A. and Oncley, S. P.: Flux Measurement with Conditional Sampling, J. Atmos. Oceanic Tech., 7, 349-352, 1990.

Coles, J. and Guilhaus, M.: Orthogonal acceleration - a new direction for time-of-flight mass spectrometry: Fast, sensitive mass analysis for continuous ion sources, TRAC-Trend Anal. Chem., 12, 203-213, 1993.

de Gouw, J. and Warneke, C.: Measurements of volatile organic compounds in the earth's atmosphere using proton-transferreaction mass spectrometry, Mass Spectrom. Rev., 26, 223-257, 2007.

Dabberdt, W. F., Lenschow, D. H., Horst, T. W., Zimmerman, P. R., Oncley, S. P., and Delany, A. C.: AtmosphereSurface Exchange Measurements, Science, 260, 1472-1481, doi:10.1126/science.260.5113.1472, 1993.
DeCarlo, P., Kimmel, J., Trimborn, A., Northway, M., Jayne, J., Aiken, A., Gonin, M., Fuhrer, K., Horvath, T., Docherty, K., Worsnop, D., and Jimenez, J.: Field-Deployable, HighResolution, Time-of-Flight Aerosol Mass Spectrometer, Anal. Chem., 78, 8281-8289, doi:10.1021/ac061249n, 2006.

Graus, M., Hansel, A., Wisthaler, A., Lindinger, C., Forkel, R., Hauff, K., Klauer, M., Pfichner, A., Rappenglück, B., Steigner, D., and Steinbrecher, R.: A relaxed-eddy-accumulation method for the measurement of isoprenoid canopy-fluxes using an online gas-chromatographic technique and PTR-MS simultaneously, Atmos. Environ., 40, 43-54, 2006.

Graus, M., Müller, M., and Hansel, A.: High resolution PTR-TOF: Quantification and formula confirmation of voc in real time, J. Am. Soc. Mass Spectr., in press, doi:10.1016/j.jasms.2010.02.006, 2010.

Guenther, A. B. and Hills, A. J.: Eddy covariance measurement of isoprene fluxes, J. Geophys. Res., 103(D11), 13145-13152, doi:10.1029/97jd03283, 1998.

Hammerle, A., Haslwanter, A., Tappeiner, U., Cernusca, A., and Wohlfahrt, G.: Leaf area controls on energy partitioning of a temperate mountain grassland, Biogeosciences, 5, 421-431, 2008, http://www.biogeosciences.net/5/421/2008/.

Hansel, A., Jordan, A., Holzinger, R., Prazeller, P., Vogel, W., and Lindinger, W.: Proton transfer reaction mass spectrometry: online trace gas analysis at the ppb level, Int. J. Mass Spectrom., 149-150, 609-619, 1995.

Herbig, J., Müller, M., Schallhart, S., Titzmann, T., Graus, M., and Hansel, A.: On-line breath analysis with PTR-TOF, J. Breath Res., 3, 027004, doi:10.1088/1752-7155/3/2/027004, 2009.

Jordan, A., Haidacher, S., Hanel, G., Hartungen, E., Märk, L., Seehauser, H., Schottkowsky, R., Sulzer, P., and Märk, T. D.: A high resolution and high sensitivity proton-transfer-reaction time-of-flight mass spectrometer (PTR-TOF-MS), Int. J. Mass Spectrom., 286, 122-128, 2009.

Karl, T., Guenther, A., Jordan, A., Fall, R., and Lindinger, W.: Eddy covariance measurement of biogenic oxygenated VOC emissions from hay harvesting, Atmos. Environ., 35, 491-495, 2001a.

Karl, T., Guenther, A., Lindinger, C., Jordan, A., Fall, R., and Lindinger, W.: Eddy covariance measurements of oxygenated volatile organic compound fluxes from crop harvesting using a redesigned proton-transfer-reaction mass spectrometer, J. Geophys. Res., 106, 24157-24167, 2001b

Karl, T., Fall, R., Crutzen, P. J., Jordan, A., and Lindinger, W.: High Concentrations of Reactive Biogenic VOCs at a High Altitude Site in Late Autumn, Geophys. Res. Lett., 28(3), 507-510, 2001c.

Karl, T. G., Spirig, C., Rinne, J., Stroud, C., Prevost, P., Greenberg, J., Fall, R., and Guenther, A.: Virtual disjunct eddy covariance measurements of organic compound fluxes from a subalpine forest using proton transfer reaction mass spectrometry, Atmos. Chem. Phys., 2, 279-291, 2002, http://www.atmos-chem-phys.net/2/279/2002/.

Karl, T., Apel, E., Hodzic, A., Riemer, D. D., Blake, D. R., and Wiedinmyer, C.: Emissions of volatile organic compounds inferred from airborne flux measurements over a megacity, Atmos. Chem. Phys., 9, 271-285, 2009, http://www.atmos-chem-phys.net/9/271/2009/. 
Lenschow, D. H. and Raupach, M. R.: The Attenuation of Fluctuations in Scalar Concentrations through Sampling Tubes, J. Geophys. Res., 96, 15259-15268, doi:10.1029/91jd01437, 1991.

Lindinger, W., Hansel, A., and Jordan, A.: On-line monitoring of volatile organic compounds at pptv levels by means of protontransfer-reaction mass spectrometry (PTR-MS) medical applications, food control and environmental research, Int. J. Mass Spectrom., 173, 191-241, 1998.

McMillen, R. T.: An eddy correlation technique with extended applicability to non-simple terrain, Bound-Lay. Meteorol. 43, 231245, 1988.

Mielke, L. H., Erickson, D. E., McLuckey, S. A., Müller, M., Wisthaler, A., Hansel, A., and Shepson, P. B.: Development of a Proton-Transfer Reaction-Linear Ion Trap Mass Spectrometer for Quantitative Determination of Volatile Organic Compounds, Anal. Chem., 80, 8171-8177, 2008.

Monks, P. S., Granier, C., Fuzzi, S., Stohl, A., Williams, M. L., Akimoto, H., Amann, M., Baklanov, A., Baltensperger, U., Bey, I., Blake, N., Blake, R. S., Carslaw, K., Cooper, O. R., Dentener, F., Fowler, D., Fragkou, E., Frost, G. J., Generoso, S., Ginoux, P., Grewe, V., Guenther, A., Hansson, H. C., Henne, S., Hjorth, J., Hofzumahaus, A., Huntrieser, H., Isaksen, I. S. A., Jenkin, M. E., Kaiser, J., Kanakidou, M., Klimont, Z., Kulmala, M., Laj, P., Lawrence, M. G., Lee, J. D., Liousse, C., Maione, M., McFiggans, G., Metzger, A., Mieville, A., Moussiopoulos, N., Orlando, J. J., O'Dowd, C. D., Palmer, P. I., Parrish, D. D., Petzold, A., Platt, U., Pöschl, U., Prévôt, A. S. H., Reeves, C. E., Reimann, S., Rudich, Y., Sellegri, K., Steinbrecher, R., Simpson, D., ten Brink, H., Theloke, J., van der Werf, G. R., Vautard, R., Vestreng, V., Vlachokostas, C., and von Glasow, R.: Atmospheric composition change - global and regional air quality, Atmos. Environ., 43, 5268-5350, doi:10.1016/j.atmosenv.2009.08.021, 2010.

Müller, M., Mielke, L. H., Breitenlechner, M., McLuckey, S. A., Shepson, P. B., Wisthaler, A., and Hansel, A.: MS/MS studies for the selective detection of isomeric biogenic VOCs using a Townsend Discharge Triple Quadrupole Tandem MS and a PTRLinear Ion Trap MS, Atmos. Meas. Tech., 2, 703-712, 2009, http://www.atmos-meas-tech.net/2/703/2009/.

Prazeller, P., Palmer, P. T., Boscaini, E., Jobson, T., and Alexander, M.: Proton transfer reaction ion trap mass spectrometer, Rapid Commun. Mass Sp., 17, 1593-1599, 2003.
Rinne, H. J. I., Guenther, A. B., Warneke, C., de Gouw, J. A., and Luxembourg, S. L.: Disjunct Eddy Covariance Technique for Trace Gas Flux Measurements, Geophys. Res. Lett., 28(16), 3139-3142, doi:10.1029/2001, 2001.

Shaw, W., Spicer, C., and Kenny, D.: Eddy correlation fluxes of trace gases using a tandem mass spectrometer, Atmos. Environ., 32, 2887-2898, 1998.

Spirig, C., Neftel, A., Ammann, C., Dommen, J., Grabmer, W., Thielmann, A., Schaub, A., Beauchamp, J., Wisthaler, A., and Hansel, A.: Eddy covariance flux measurements of biogenic VOCs during ECHO 2003 using proton transfer reaction mass spectrometry, Atmos. Chem. Phys., 5, 465-481, 2005, http://www.atmos-chem-phys.net/5/465/2005/.

Turnipseed, A. A., Huey, L. G., Nemitz, E., Stickel, R., Higgs, J., Tanner, D. J., Slusher, D. L., Sparks, J. P., Flocke, F., and Guenther, A.: Eddy covariance fluxes of peroxyacetyl nitrates (PANs) and $\mathrm{NO}_{\mathrm{y}}$ to a coniferous forest, J. Geophys. Res., 111, D09304, doi:10.1029/2005jd006631, 2006.

Warneke, C., de Gouw, J. A., Kuster, W. C., Goldan, P. D., and Fall, R.: Validation of Atmospheric VOC Measurements by Proton-Transfer- Reaction Mass Spectrometry Using a GasChromatographic Preseparation Method, Environ. Sci. Technol., 37, 2494-2501, doi:10.1021/es026266i, 2003.

Warneke, C., de Gouw, J. A., Lovejoy, E. R., Murphy, P. C., Kuster, W. C., and Fall, R.: Development of Proton-Transfer Ion Trap-Mass Spectrometry: On-line Detection and Identification of Volatile Organic Compounds in Air, J. Am. Soc. Mass Spectrom., 16, 1316-1324, 2005a.

Warneke, C., Kato, S., de Gouw, J. A., Goldan, P. D., Kuster, W. C., Shao, M., Lovejoy, E. R., Fall, R., and Fehsenfeld, F. C.: Online Volatile Organic Compound Measurements Using a Newly Developed Proton-Transfer Ion-Trap Mass Spectrometry Instrument during New England Air Quality StudyIntercontinental Transport and Chemical Transformation 2004: Performance, Intercomparison, and Compound Identification, Environ. Sci. Technol., 39, 5390-5397, doi:10.1021/es050602o, 2005b.

Wohlfahrt, G., Hammerle, A., Haslwanter, A., Bahn, M., Tappeiner, U., and Cernusca, A.: Seasonal and inter-annual variability of the net ecosystem $\mathrm{CO}_{2}$ exchange of a temperate mountain grassland: effects of weather and management, J. Geophys. Res. 113, D08110, doi:10.1029/2007JD009286, 2008. 